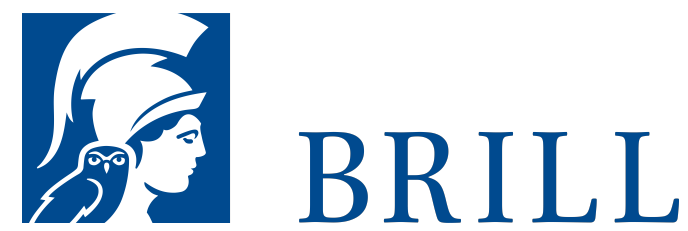

\title{
Fotografie als theoretisches Objekt
}

Bildwissenschaft - Medienästhetik - Kunstgeschichte

Author: Martina Dobbe

Der Band fragt nicht nach der Fotografie, nicht nach dem Medium Fotografie und nicht nach ihrer Geschichte. Statt dessen erörtert er interdisziplinär das bildtheoretische Potential einer Beschäftigung mit dem Fotografischen in Fotografie und Video. Vier Leitmotive gliedern das Buch: Gefragt wird nach dem Fotografischen im klassischen Paragone der Künste, nach dem Fotografischen im Kontext der Theorie von Reproduktion und Appropriation, nach dem Fotografischen im modernistischen Diskurs um Medienspezifik und Postmedialität sowie nach dem Fotografischen als dispositive Struktur. In der Auseinandersetzung mit fotografischen Arbeiten (Acconci, Evans, Graham, Warhol u.a.) wird deutlich, daß das Fotografische in seiner apparativen Bedingtheit auf besondere Weise auf die Konditionen des Bildlichen im Abbildlichen zu lenken vermag.

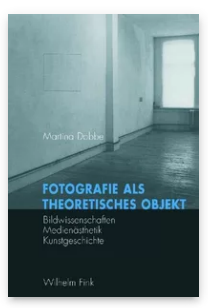

Pages: 344

Seiten, $40 \mathrm{~s} / \mathrm{w}$

Abb.

Language:

German

Subjects:

General, Media

Studies

Publisher: Brill |

Fink

E-Book (PDF)

Released online: 16 Sep 2019

ISBN: 978-3-

8467-4446-8

List price

USD \$63.00

Paperback

Publication date:

24 Oct 2007

ISBN: 978-3-

7705-4446-2

List price

USD \$63.00 
For more information see brill.com

Order information: Order online at brill.com +44330 333 0049 | customerservices@brill.com Submission information: brill.com/authors

Titles published by Brill | Fink, Brill | mentis or Brill | Schöningh: +49(o)715413279216| brill@brocom.de 